\title{
Visual Analysis of Indonesian Criminal Packaging Toy
}

\author{
Satria Indra Praja Persada S.Ds., M.M \\ Visual Communication Design, \\ School of Design, \\ Universitas Komputer Indonesia \\ satriaindra@email.unikom.ac.id
}

\begin{abstract}
Packaging has a simple function of protecting the product. Packaging also makes it easier for the product to be carried on a long journey, but as the era changes packaging not only serve as a protector and make it easier for the product to carry but the packaging must also be attractive. The packaging must be attractive so that it can compete with other products so that consumers choose the product. Therefore, the packaging must have graphics that match the product, can describe the product, and can explain the advantages of the product so that it is easy to remember and purchased by consumers. This research was made with data collection methods sourced from electronic networks, which were used as the main source of information. In this study, the object of study is a toy with local wisdom. This toy is interesting to choose because this toy takes on the original character of Indonesia. Where this character is no stranger and very well known by the people of Indonesia and has even been a conversation at Indonesia and abroad because it contains Indonesian controversial figures, such as Sumanto and Robot gedek which are killers and cannibals from Indonesia. A good packaging design can make the product look attractive and can bring the uniqueness of the product to attract the attention of potential buyers.
\end{abstract}

Keywords - Packaging, toys, design, Indonesia

\section{INTRODUCTION}

Packaging has been used for a long time both as a protector of products and a container to facilitate products when taken [1]. As the era of competition in the business world becomes sharper, packaging functions not only become a protector and a container of products, but more than that packaging must be able to attract consumers [2]. Packaging must be able to compete with other products, because of that in the making of the packaging the manufacturer must consider other factors in making the packaging and the manufacturer must also consider what visual elements will be displayed. This needs to be considered so that the product attracts consumers and can compete in the market. The writer is focusing on product packaging of the new type of toy. As the tittle of this research is "Visual Analysis Of Criminal Toy Packaging", that is about Indonesian criminal toy package.

Main subject of this research is to analyzing of toy packaging of Indonesian product. The purpose [3] of the analysis of toy packaging with Indonesian wisdom is to know that packaging is not only a protective device [4] and a product container, but there are other factors besides that which can be used in marketing these products, so that the product is interesting and remembered by consumers and even used as collections by consumers. There is another research about the analysis of packaging products such as, research by Pinya Silayoi [5], Gordon L. Robertson [6], and Victor J. Bertrand [7], but there is still no research about product with Indonesian wisdom. Toy products with Indonesian wisdom with Goodguysneverwin Brand is one example of toys that prioritize packaging design [8] that can tell stories and explain the uniqueness of the product so that the product has more selling value compared to other products. With this understanding, it is expected that the concept of packaging design like this can be applied by the makers of products in designing their product packaging to have more selling value compared to others.

\section{METHOD}

The method used in this study is a descriptive qualitative method, the qualitative method itself is a method in which researchers examine the status of a group of people, objects, a condition, a system of thought or class of events that exist in the present. The purpose of this research with a descriptive method is to make a description, description, and illustrate systematically, factually and accurately about the facts, characteristics, and relationships between the phenomena under study. Meanwhile, according to Sugiyono [9] stated that a descriptive method is a method used to describe or analyze data from a research but is not used to make broader conclusions. Then based on this understanding the data is processed with objects and adapted to previous research to determine the meaning and quality from the visual elements that make up the packaging and then describe it.

This analysis method uses the visual element analysis method where the product in question will be matched with existing theories and then will be described and determined whether the product is good or not, the theory used is a : 1 . color design packaging element, 2. forms, 3. typography, 4. layout, 5. brand / klimchuk identity (2006) and must consider factors such as 1. Economic factors, 2. distribution factors, 3 . economic factors, 4. esthetic factors, 5. identity factor, this analysis will be divided into 3 steps, namely 1 . data collection that is getting data in the form of products and theories about packaging, 2. data processing where the data collected will be broken down based on visual elements, 3 . 
visual elements that have been broken down will be adjusted to the theory about packaging and then described and determined whether the packaging is good or bad.

\section{A. Data Collecting}

The first stage is data collection where at this stage researchers are looking for indopsycho toy packaging produced by Goodguysneverwin through internet media and searching literature about packaging through books, journals, and scientific research on the visual communication design $\&$ economy articles on visual elements and functions of packaging itself, some books from related print media and internet media sources are also used.

\section{B. Data Processing}

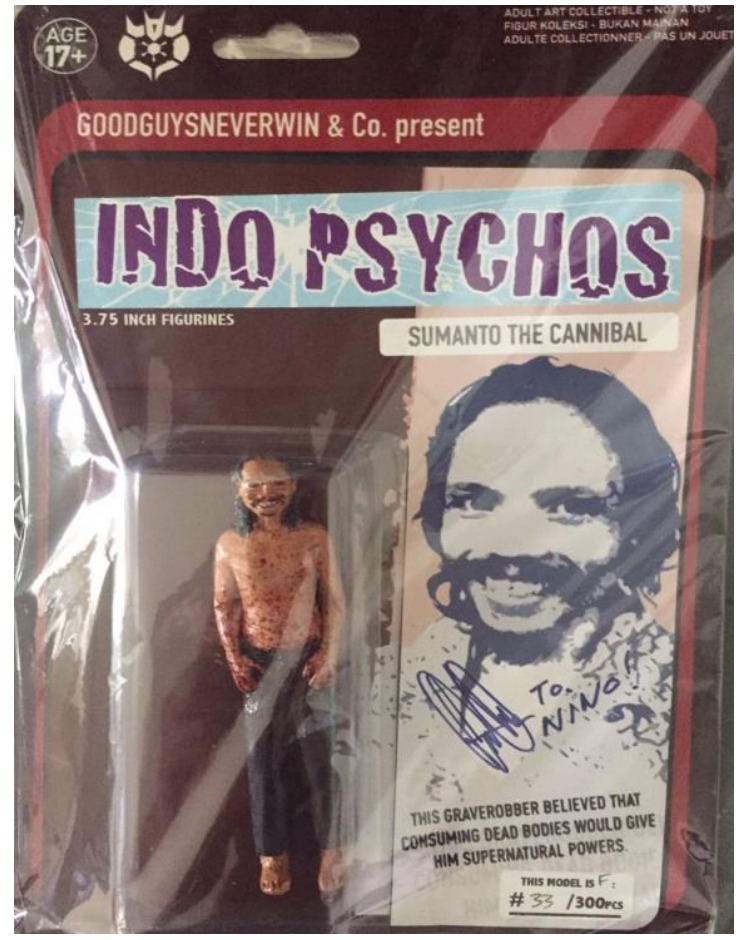

Fig. 1. Indo Psychos Package

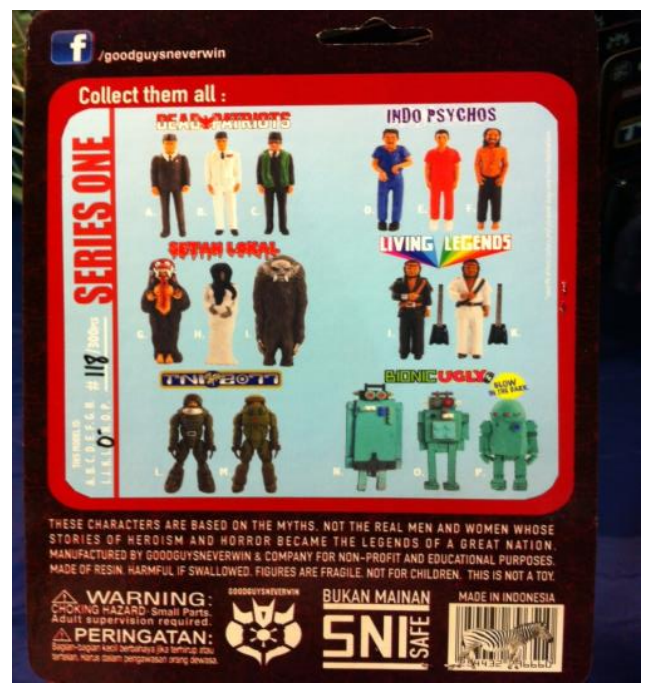

Fig. 2. Back Package
In this stage the data that has been collected is then processed using existing literature studies, then the packaging is observed and the packaging of the product is broken down according to the visual elements of the package into several parts.

Visual elements of the product will be described and adapted to the existing literature to find out the results of the product visual elements that exist in the packaging if it has been broken down using packaging theory (Klimchuck, 2006) is divided into several parts, consisting of:

\section{Colors}

The colors used in this packaging tend to be dark and use black as the dominant one, then the color is red and the writing in this package is white.

\section{Form / Material}

The shape of this package is a box with a blunt angle on each side and uses thick cardboard and plastic material as a protection from the product.

\section{Brand \& Logo}

Brands \& Logos in this package are located above in addition to logotype-shaped age information and are white.

4. Illustration

The illustrations used in this package are in the form of photos and are made by editing photos of packaged products and there is an explanation of the figure below the illustration.

\section{Typography}

Typography used in this package consists of several types, namely decorative and sans serif where typography used is extended or high type up.

\section{Layout}

The layout of this product consists of the front and back on the front of the product there is information and logos on the top, the tagline of the product is below it and the product is at the bottom of the tagline beside the product there is an explanation of the product character and in the section there is a warning on the bottom right of the product, then on the back there is a Facebook address to order the product placed in the top left corner and below there are other products from Goodguysneverwin and below there is an explanation of the toy produced by Goodguyneverwin and below there is information such as warning, barcode and the brand of the product.

This product has a tagline "INDOPSYCHO" where this product is a toy about psycho people in Indonesia where this toy includes action figures with psychological thriller classification

\section{RESULTS}

The results obtained from the study of the packaging of the Goodguysneverwin indopsycho version of the Toys are as follows:

\section{Color}

The color used in the packaging is appropriate because it can explain the concept of a product that is a toy product from the concept of a thriller. 


\section{Form/ Material}

The shape used in the packaging is appropriate because the selected shape makes it easy for the product to be easily displayed and shows the shape of the toy The material used by the packaging is appropriate because the material can protect the product, the price of the material is also quite affordable.

3. Brand \& Logo

Brands \& logos in packaging are not good because they are less visible because the brand or logo has a color that does not contrast with the packaging.

4. Illustration

The illustration used in the packaging is appropriate because it can communicate and explain the product.

5. Typography

Typography used is appropriate because it can explain the concept of the product.

6. Layout

Layout of the composition of illustrations and typography is appropriate because it can balance all the visual aspects that exist from the packaging.

\section{DISCUSSION}

Packaging is an important part of a product not only as a protector and a container of good packaging products must also be able to attract buyers and can explain what the product is. so that consumers can identify the product [10].

The visuals seen from the packaging will be classified into seven parts which will be analyzed using theories regarding visual elements and factors of packaging.

\section{Color}

One visual element is color, Color is an important factor in packaging. According to Morton in Klimchuck (2006) on packaging this product uses black, red and dark tend to be dark and for typography is used in white so that it looks contrast because it is placed on a background that tends to dark. When viewed from a good packaging communication factor is a package that can communicate product from the packaging. According to the statement because this toy is a toy from the figure of a psycho and thriller-themed, the color is suitable because the dark and red looks can be positioned with the same blood. This color is also often used in thriller-themed products and white is used in typography used to look contrast and clear because it is placed on a dark background, this shows that the color of this packaging has met the factors.

\section{Form/ Material}

The shape of the package above the box with a blunt angle from the ergonomics factor of this packaging is quite good because it makes the packaging easy to carry and easily displayed and easy to carry. And with this blunt angle makes this packaging harmless, and the material used by the toy packaging is made of cardboard and plastic, material selection is in accordance with the security factor because the material can protect the product according to its own product type, and when viewed from the factor. Even the economics of the material prices are also quite affordable so it does not cost money for the production of packaging and the distribution factor is also appropriate because the packaging is not so heavy and takes too many place so it is easy to distribute.

3. Brand \& Logo

Brands \& logos are located on the front of the top left, the $\operatorname{logo}$ is white and above it is written with white logotype. The position of the logo here is good because it is placed above so it is easy to see but unfortunately the color and shape of the logo is not good because it is similar to other visual elements so it looks unified and lacks striking, the shape of the logo is complicated and less understood so that for brands \& logos here it feels less appropriate with Illustration because it does not match the identity factor because the logotype's complicated logogram is also made separate so that the $\log$ is difficult to recognize.

\section{Illustration}

The illustration on the toy packaging is in addition to the toy, this is in accordance with the identity factor because it makes the product easily recognizable and with blue and red illustrations, and depicts characters from the product being packaged. Illustrations made from photos and uses editing photos. Photos taken are photos when the character was arrested or while in prison, giving a creepy impression that matched the image of the product figure as a thriller toy. Then under the picture was written the explanation of the character explaining who and what was done from the character, was in accordance with the communication factor because the packaging can explain the product. Then behind the package there is an illustration in the form of other products from Goodguysneverwin. This is also in accordance with the communication factor because the packaging can communicate other products so that the product buyer can complete the collection and make another purchase.

\section{Typography}

Typography used in packaging consists of headlines, sub headlines, body text. The written headline "indopsycho" uses decorative typefaces. The font is made thick and high (extended) is good because it is filled with a portrait packaging so it looks full and bold font is also good because it makes typography clearly visible, and typography is broken and seems damaged typography. According to the product made especially in this identity factor this typography emphasizes that the product is a thriller toy, sub headlines such as "warning" etc. using extended sans type and thick stripes are in accordance with the portrait design (extends down) and with thick fonts making this subhead line easy to read in accordance with aesthetic and communication factors because it makes the packaging easy to read and the aesthetics look good. Body text consisting of character explanations is made with an extended sans serif font with medium line thickness and can be read well. 
6. Layout

The layout consists of illustrations and typography arranged in such a way as the headline position on the toy and made large so that the toy is clearly visible and the illustration along with the explanation of the toy is beside the toy, so that the explanation of the toy is well explained. Products become easily recognizable and easy to read and have good aesthetics because the distribution of visual elements is balanced.

\section{CONCLUSION}

Based on the analysis that has been carried out using visual analysis the description of packaging and packaging factors of indopsycho toys have good visuals and contain factors that must be considered in making packaging. So that they can convey the message from the toy product itself, but this toy has disadvantages in the part of the brand / logo that is not good because the logo is complicated and difficult to recognize. In this packaging the toy that becomes a focal point can be explained well all the visual elements in this package support this toy product so it is impressive and explains that this toy is a toy thriller and it seems scary in accordance with the toy product itself. This research is expected that producers in making packaging not only consider the protection factor but there are other factors and other visual elements that must be considered so that the product can compete in the market.

\section{REFERENCES}

[1] Diana Twede. 2005. "The Origins of Paper Based Packaging" (PDF). Archived from the original (PDF) on July 16, 2011. Retrieved March 20, 2010.

[2] Soroka 2002. Fundamentals of Packaging Technology, Institute of Packaging Professionals

[3] https://courses.lumenlearning.com/boundless-marketing/chapter/ packaging/

[4] Choi, Seung-Jin; Burgess. 2007. "Practical mathematical model to predict the performance of insulating packages". Packaging Technology and Science. 20 (6): 369-380. doi:10.1002/pts.762.

[5] Pinya Silayoi, Mark Speece. 2007. "The importance of packaging attributes: a conjoint analysis approach", European Journal of Marketing, Vol. 41 Issue: 11/12, pp.1495-1517, https://doi.org/10.1108/03090560710821279

[6] Gordon L. Robertson. 1998. Food Packaging: Principles and Practice. CRC Press

[7] Victor J. Bertrand. 1990. Toy Packaging.

[8] https://medium.com/digital-packaging-experiences/the-psychology-ofproduct-packaging-29bf52ad6220

[9] Sugiyono. 2008. Metode penelitian pendidikan: (pendekatan kuantitatif, kualitatif dan R \& D). Bandung: CV Alfabeta

[10] Klimchuk, Marianne dan Sandra A. Krasovec. 2006. Desain Kemasan. Jakarta: Erlangga.

[11] Kotler dan Keller. 2009. Manajemen Pemasaran. Jilid I. Edisi ke 13. Jakarta: Erlangga.

[12] Kotler, Philip. 1999. Manajemen Pemasaran. Jilid II. Edisi Milenium. Jakarta: Prenhallindo.

[13] Rangkuti, Freddy. 2005. Analisis SWOT: Teknik Membedah Kasus Bisnis. Jakarta: Gramedia

[14] Simamora, Bilson. 2007. Panduan Riset dan Perilaku Konsumen. Jakarta: Gramedia.

[15] Louw, A. \& Kimber, M. 2007. The Power of Packaging, The Customer Equity Company. 